\title{
Effects of religious setting on cooperative behavior: a case study from Mauritius
}

\author{
Dimitris Xygalatas* \\ Department of Culture and Society, Interacting Minds Centre, and Religion, Cognition and \\ Culture research unit (RCC), Aarhus University, Denmark and LEVYNA Laboratory for the \\ Experimental Research of Religion, Masaryk University
}

\begin{abstract}
Social scientists and folk wisdom have both claimed that there is an association between religiosity and prosocial behavior, but hard evidence for such a relationship is limited. Studies show that religiosity is correlated with selfreported prosociality; however, this relationship is not very clear when it comes to observed prosocial behaviors. Experimental studies reveal a link between religious priming and prosocial behaviors, and these effects are evident irrespective of the degree of religiosity of the participant. Building on and combining the strengths of previous field designs, I report on the results of a field experiment in Mauritius examining the effects of religious environments on cooperation in a naturalistic setting. These results were consistent with previous findings that religious cues increase cooperation. Importantly, this effect was not dependent on degrees of prior religiosity. Plausible interpretations of such effects are discussed.
\end{abstract}

Keywords: cooperation; Mauritius; prosociality; experimental anthropology; religion

\section{Introduction}

Social theorists have long claimed that religion promotes prosociality. Religious systems have often been seen as socializing mechanisms that control innate selfdestructive urges (Freud, 1927/1961), promote moral actions (James, 1902/1985), enforce solidarity (Durkheim, 1912/1995), and maintain social order (Skinner, 1969; Turner, 1969). However, it is not clear exactly which aspects of religion contribute to enhancing prosocial behaviors and attitudes. There is a widespread belief in both scholarly and folk views of religion that religious people are more prosocial, and it has been shown that religious people are perceived as more trustworthy (de Dreu, Yzerbyt, \& Leyens, 1995; Orbell, Goldman, Mulford, \& Dawes, 1992; Saroglou, Pichon, \& Trompette, 2005; Tan \& Vogel, 2008). Nonetheless, actual evidence that religious people are more prosocial is limited and mostly indirect.

While a consistent correlation between religiosity and self-reported prosociality has been demonstrated (Friedrichs, 1960; Furrow, King, \& White, 2004; Gronbjerg \& Never, 2004; Guiso, Sapienza, \& Zingales, 2003; Koenig, McGue, Krueger, \& Bouchard, 2007; Lam, 2002; McCullough \& Worthington, 1999; Morgan, 1983; Saroglou, Delpierre, \& Demelle, 2004), when behavioral measures are used this relationship becomes dubious. Although certain experimental studies have shown a

*Email: xygalatas@mac.com 
positive correlation between intrinsic religiosity and prosocial behavior (Saroglou et al., 2005; Soler, 2012), most others show that such a correlation is either nonexistent (Anderson, Mellor, \& Milyo, 2010; Batson, Oleson, \& Weeks, 1989; Batson, Schoenrade, \& Ventis, 1993; Darley \& Batson, 1973; Eckel \& Grossman, 2004; Grossman \& Parrett, 2011; Johansson-Stenman, Mahmud, \& Martinsson, 2009; Malhotra, 2010; Orbell et al., 1992; Spilka, Hood, Hunsberger, \& Gorsuch, 2003; Tan, 2006), or can be attributed to other factors such as in-group bias (Bulbulia \& Mahoney, 2008; Sosis \& Ruffle, 2003; Tan \& Vogel, 2008). Some studies even show a negative correlation between the two variables (Batson, Floyd, Meyer, \& Winner, 1999; Goldfried \& Miner, 2002; Jackson \& Esses, 1997).

Furthermore, most studies that explore religious prosociality rely on correlational designs, which make it hard to determine whether religiosity has any causal influence on prosociality (Norenzayan \& Shariff, 2008). More precise designs might reveal a different picture. For example, Ahmed (2009) found that theology students at Indian madrasah were more prosocial compared to social science students at a secular school. However, the study design did not directly evaluate the causal role of religion, because religious students were tested in the madrasah while secular students were tested in a secular school. Thus, it is not possible to know whether increased prosociality was observed due to higher religiosity or due to exposure to a religious setting. In fact, in a controlled study, Ahmed and Salas (2008) found that implicit religious primes increased prosociality regardless of participants' religiosity.

An alternative hypothesis, then, is that the prosocial (as well as anti-social: Ginges, Hansen, \& Norenzayan, 2009) effects of religion lie not in religiosity per se but in the implicit contextual cues that religious environments provide (Bulbulia, 2010; Mazar, Amir, \& Ariely, 2008). In fact, it has been demonstrated that priming with religious concepts reduces cheating (Ariely, 2008, 2012; Bering, McLeod, \& Shackelford, 2005; Randolph-Seng \& Nielsen, 2007) and promotes trust and altruism (Ruffle \& Sosis, 2010; Shariff \& Norenzayan, 2007), and that those effects typically hold independently of participants' degree of religiosity. Furthermore, several studies have documented a link between participation in religious activities and prosociality (e.g., Monsma, 2007; Orbell et al., 1992). In one such study (Malhotra, 2010), religious bidders at auctions responded more frequently than non-religious bidders to an appeal to continue bidding for charitable causes. However, a careful examination of the data revealed that this effect occurred only on days when they had previously attended church, which the author termed the "Sunday Effect." This suggests that religious bidders were not inherently more charitable, but rather that a religious context increased their prosocial dispositions.

The study presented here used an economic experiment in a naturally relevant setting to evaluate two hypotheses of religious cooperation: (A) religious belief promotes cooperation, and/or (B) religious environments/cues promote cooperation. In accordance with the latter hypothesis, the predictions tested were that (B1) being situated in a religious context would lead to more cooperative behavior compared to being in a secular context and that (B2) this effect would exist across individual degrees of religiosity.

\section{Background}

The study was conducted in Mauritius, a small island nation in the Western Indian Ocean where I have been conducting ethnographic research for a total of nine months since 2009. The setting was Pointe aux Piments, a large village of 5000 people 
on the northwest coast. Mauritius has a predominantly Hindu population (approximately 50\%). There are also large numbers of Muslims (16.6\%), Roman Catholics (23.6\%), as well as other Christians (8.6\%) and several smaller religious groups (Central Statistical Office of Mauritius, 2002). The Hindu majority is further subdivided into numerous religious traditions (Sanatanists, Arya Samajists, Tamils, Telegus, Marathis, etc.). More generally, Mauritius is an ethnic melting pot, and one of the most socially diverse countries in the world (Eriksen, 1994, 1998; Okediji, 2005). Uninhabited until the eighteenth century, the island lacks any indigenous population and the majority of its inhabitants are the descendants of slaves or indentured laborers brought from Asia and Africa by French and British colonial rulers (Allen, 1999), living alongside people of European and mixed descent. Ethnic and cultural heterogeneity is also reflected in language. There is tremendous linguistic diversity on the island, and the average young Mauritian uses three or four languages on an everyday basis. English is the de facto language of government, education, and administration, while French dominates the media and the arts. However, the lingua franca is Mauritian Creole, which is what most locals publicly speak with each other. Moreover, most Mauritians also speak at least one other language at home and/or the temple, such as Hindi, Bhojpuri, Tamil, Telugu, Marathi, Gujarati, Urdu, Arabic, Mandarin, or Hakka.

Despite Mauritius' great ethnic, cultural, linguistic, and religious diversity, conflict between the various ethnic or religious groups is limited; indeed, Mauritius is often discussed as an example of successful multi-ethnic cohabitation (Christopher, 1992). Regardless of its idyllic portrayals, however, distrust and suspicion remain generally high in Mauritian society, not only between (Eriksen, 1998) but also within groups (Ware \& Dethmer, 2009). I observed such distrust during the course of my ethnographic fieldwork in Mauritius. In my everyday conversations, I found that the locals frequently and openly doubted the intentions of others in every domain of life from employers constantly suspecting their employees of stealing from them, to temple priests removing the light bulbs outside the temple and locking them inside before closing, to conspiracy theories about the government putting old people to death in order to save on pensions. Despite this overall suspicion, however, conflicts remained limited and the locals seemed to collaborate often in order to tackle common problems.

One of the areas where collaborative interaction appears abundant is in the realm of religion. Most Mauritians spend significant time on religious activities. Notably, organizing prayers, pilgrimages, and rituals requires the coordination of unpaid volunteer labor. Rough estimations derived from interviews with over 100 locals suggest that each spends a staggering average of more than 700 hours a year engaging in temple activities, private rituals, and public religious festivals. These activities seem to function as a basic means of socialization across ethnic, linguistic, and cultural divisions, alongside schooling, the workplace, and the local bar or restaurant. Intriguingly, it is common in Mauritius to see adherents of one religion attending the temples and rituals of another, suggesting that religious volunteering might not be a bounded phenomenon (Eriksen, 1998; Xygalatas et al., in press).

\section{Materials and methods}

An economic experiment was used to assess the hypothesis that religious environments increase cooperation. Economic games offer a powerful method for investigating cooperative preferences both in laboratory and field settings (Henrich 
et. al., 2004). Although not a natural measure (Gurven \& Winking, 2008), they are widely used as a proxy for cooperation because they measure actual behaviors rather than self-reported attitudes. Thus, instead of simply being asked to imagine their reaction to hypothetical scenarios, participants must put their money where their mouths are.

The specific task selected for this study was a bargaining game that belongs to a class of experiments called common-pool resource games (Budescu, Rapoport, \& Suleiman, 1992; Messick, Allison, \& Samuelson, 1988; Ostrom, Gardner, \& Walker, 1994). In such a game, participants decide how much to withdraw from a shared account, but each individual's return also depends upon the request of the other player. Some level of cooperation is necessary, as players receive a return only if the aggregate request does not exceed the value of the common pool. The amount claimed is considered to provide a realistic prosocial measure, one that simultaneously incorporates a regard for others with a regard for oneself (Sosis \& Ruffle, 2003) - the more restrained a player is, the more likely a collective reward will be obtained.

In addition to offering a realistic measure for cooperative exchange, this game has the benefit of resonating with everyday Mauritian experience. Bargaining over who gets how much of a collective resource is a common part of everyday exchanges in Mauritius. Furthermore, the mutual cautiousness that pervades many economic transactions necessitates constant attempts to predict and analyze the other party's reasoning. Thus, although participants had never taken part in economic games before, they seemed to possess adequate implicit knowledge to negotiate the task, an assumption which was confirmed by participants' performance and understanding of the numerical outcome of the game (all participants passed the numerical test by successfully calculating their earnings).

The type of common-pool resource game used in this experiment was adapted from Sosis and Ruffle's field study of ritual and cooperation (2003). In this task, two anonymous participants from different groups played simultaneously, independently deciding which amount to withdraw from a common pot of 500 Mauritian Rupees (approximately $\$ 18$, roughly equivalent to five days' minimum pay of an unskilled worker). One group of participants was situated inside a Hindu temple; another group was situated inside a local restaurant. If the total amount claimed by both players exceeded 500 rupees, neither player would receive anything. Conversely, if the aggregate was less than 500 rupees, any amount remaining in the pot would be increased by $50 \%$ and then split between the two players.

The sample consisted of 62 participants ( 33 male, 29 female, mean age $=34.45$, $\mathrm{SD}=14.71$ ), all local inhabitants and adherents of Sanatanist Hinduism. Participants were recruited by local assistants, who solicited the first people that passed by some of the most frequented parts of the village. Each participant from the temple was matched with one from the restaurant, but the two players never saw each other. The first member of each pairing was randomly assigned to either the religious or the secular venue with the toss of a coin. Immediately after the first player was led to that venue (both venues were within walking distance from the site of recruitment), the assistants recruited the second player, who was led to the other venue. Participants neither knew the identity nor the location of the other player. To ensure anonymity and to avoid confounds from prior familiarity among participants, only one member of any given group or family was recruited. 
The two venues were roughly similar in terms of physical dimensions and spacial arrangement; each consisted of a single room with seating facilities and an internal door leading to a secluded space which is normally out of bounds for the public - the sanctuary and the kitchen, respectively. Both venues were empty and similarly lit at the time of the experiment. There were no religious symbols in the restaurant.

Upon arriving at their venue, participants were informed about the experiment and provided written consent. They were told that they would play a game in which they would have the opportunity to earn some money, and that the other player would be located in some other, unspecified place. They were informed that they would remain anonymous and would never find out the identity of the other player. Instructions were read aloud both in English and also in each participant's primary language by a local interpreter. The rules of the game were stated as follows:

\begin{abstract}
You are playing for 500 Rupees. Both you and the other player can decide to take as much money as you wish from those 500 . Whatever money you decide to get, you can keep. However, if the total amount of money that both of you decide to get is more than 500 , you both lose and no one receives any money. For example, if you take 400 Rupees and the other player takes 300 Rupees, the total is 700 , so you both get nothing and the game is over. If the total amount is not more than 500 , then you both keep the amount you have chosen. In addition, any money that remains in the box will be increased by $50 \%$ and then divided between the two of you. For example, if each of you chooses to take 100 , then the remaining amount is $500-200=300$. We add $50 \%$, so we get 450 . You can then split this amount $(450 / 2=225)$, so you will finally receive $100+225=325$.
\end{abstract}

Players were then asked if they had understood the rules and whether they had any questions, and were then instructed to make their final decision. After the decision was recorded, the experimenters asked players to state the reason (only one) for deciding on this amount and how much they expected the other party to request. The first experimenters to finish called the other venue on the phone to indicate that a decision had been made (without revealing the amount requested). When the other venue also had a final decision, they rang back and experimenters simultaneously conveyed their decisions to each other. There was no direct communication between participants at any point. Players were then notified about the other party's decision and, to test their numerical reasoning ability and understanding of the game, were asked to calculate their own earnings. All players performed the calculation successfully. Before leaving, participants were asked to fill in a form with demographic information, received their earnings, and were thanked for participating.

Religiosity was operationalized using self-reported intensity of belief and reported frequency of ritual practices. Participants provided ratings of religiosity on a scale of one to ten and estimates of engagement in ritual activities in hours per week. Although religiosity is a very complex concept and no perfect measure of it exists, a strong correlation between reports on religiosity and engagement in religious activities $(\mathrm{r}=.63, \mathrm{n}=62, \mathrm{p}<.001)$ indicated that the two variables were consistent with each other.

The data were collected over two field sessions, one in April 2011 and one in January 2012. No differences were found between the two sessions in terms of either claims $(\mathrm{t}(60)=.26, \mathrm{p}<.80)$ or expectations $(\mathrm{t}(60)=1.60, \mathrm{p}<.11)$. In order to assess whether earlier players might have affected the decisions of later players by discussing the experiment, I conducted a Pearson correlation between date and 
amount claimed, which showed no significant interaction $(\mathrm{r}=.03, \mathrm{p}=.82)$. However, four participants were excluded from the sample after revealing that they had discussed the experiment with other players.

\section{Results}

The first prediction (B1), that players in the religious venue would be more cooperative compared to those in the secular venue, was confirmed (Figure 1). Those who played in the temple claimed an average of 170.32 rupees $(\mathrm{SD}=56.08)$ compared to 231.45 rupees $(\mathrm{SD}=66.76)$ claimed by those in the restaurant, a difference that was highly significant $(\mathrm{t}(60)=3.90, \mathrm{p}<.001)$. There were no significant differences in the amount claimed between genders $(\mathrm{t}(60)=.37, \mathrm{p}=.71)$. A regression analysis showed no interaction between age and amount claimed $(\mathrm{F}(1,60)=.06, \mathrm{p}=.81)$.

The second prediction (B2), that degrees of religiosity would not affect levels of cooperation, was also confirmed. No significant differences in religiosity $(\mathrm{t}(60)=.16$, $\mathrm{p}=.88)$ or religious practices $(\mathrm{t}(60)=.11 ; \mathrm{p}=.91)$ were found between the two groups. To control for any interactions of claims and religious predisposition or familiarity effects, regression analyses showed no effects of religiosity $(\mathrm{F}(1,60)=.00$; $\mathrm{p}=.99)$ or frequency of religious practices $(\mathrm{F}(1,60)=.34 ; \mathrm{p}=.56)$ on the amount claimed across both venues.

When participants were asked to predict how much the other party would claim, the mean expectation for those in the temple was 234.51 rupees $(\mathrm{SD}=59.64)$, while

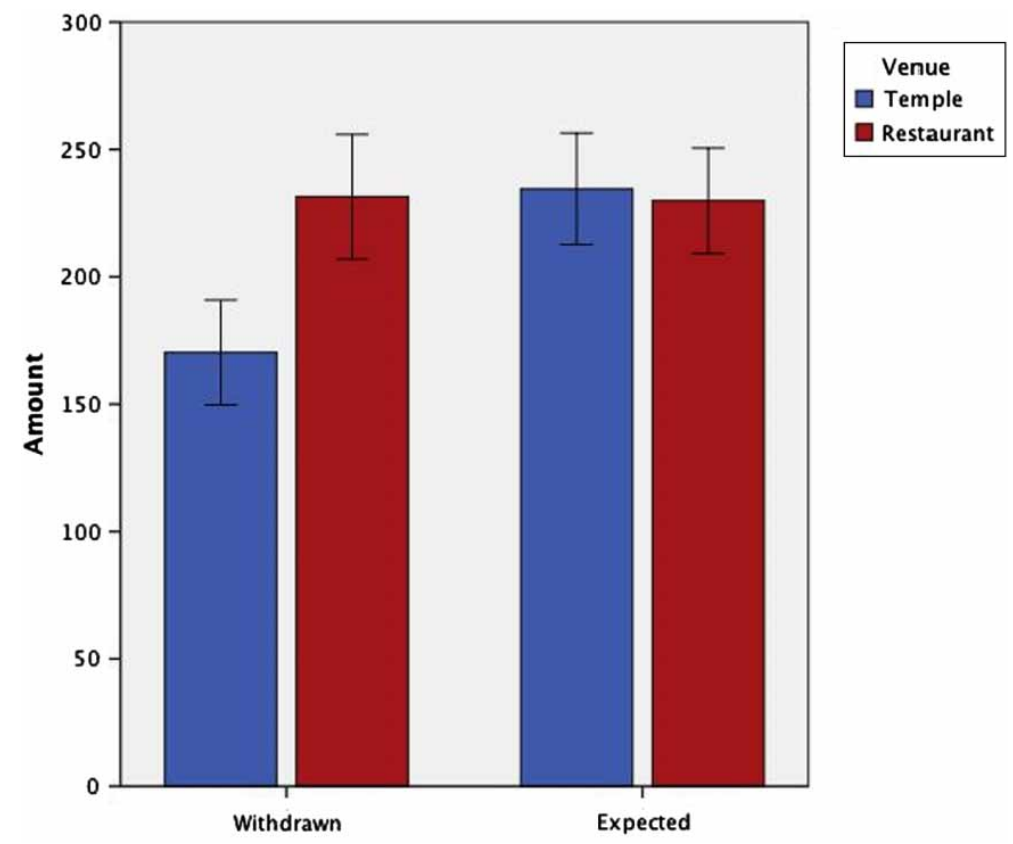

Figure 1. Mean amount in Mauritian rupees withdrawn from the common pool by each player and expected for the other player to withdraw. Error bars: 95\% CI. 
the mean expectation for those at the restaurant was 229.84 rupees $(\mathrm{SD}=56.43)$, a difference that was not significant $(\mathrm{t}(60)=.32, \mathrm{p}=.75)$. Pearson correlations revealed no significant interaction between claims and expectations across $(\mathrm{r}=.11, \mathrm{n}=62$, $\mathrm{p}=.40$ ) and within venues (temple: $\mathrm{r}=.23, \mathrm{n}=31, \mathrm{p}=.20$; restaurant: $\mathrm{r}=.06$, $\mathrm{n}=31, \mathrm{p}=.74)$, suggesting that differential claims at the two venues were not driven by risk aversion. Finally, there were no effects of religiosity $(\mathrm{F}(1,60)=.54 ; \mathrm{p}=.47)$ or frequency of religious practices $(\mathrm{F}(1,60)=1.62 ; \mathrm{p}=.21)$ on the amount expected for the other party.

Analysis of the qualitative data obtained from interviews showed that when asked to justify their decision, those who played in the temple tended to evoke fairnessrelated terms more frequently $(48.4 \%)$ than those in the restaurant $(19.4 \%)$. Conversely, those who played in the restaurant explained their choice in terms of strategic thinking terms (typically referring to "strategy", "tactics", or "logic") more frequently $(67.7 \%)$ than those who played in the temple $(48.4 \%)$. A chi-square test revealed that these differences were significant: $\chi 2(2)=6.66, p<.05$ (Fisher's Exact: $<.01$; see Figure 2).

\section{Discussion}

The effects of religious primes in promoting prosocial behavior have been previously demonstrated in the laboratory (Ahmed \& Salas, 2008; Mazar et al., 2008 Pichon, Boccato, \& Saroglou, 2007; Randolph-Seng \& Nielsen, 2007; Shariff \& Norenzayan, 2007). This study extended these findings to an ecologically relevant setting.

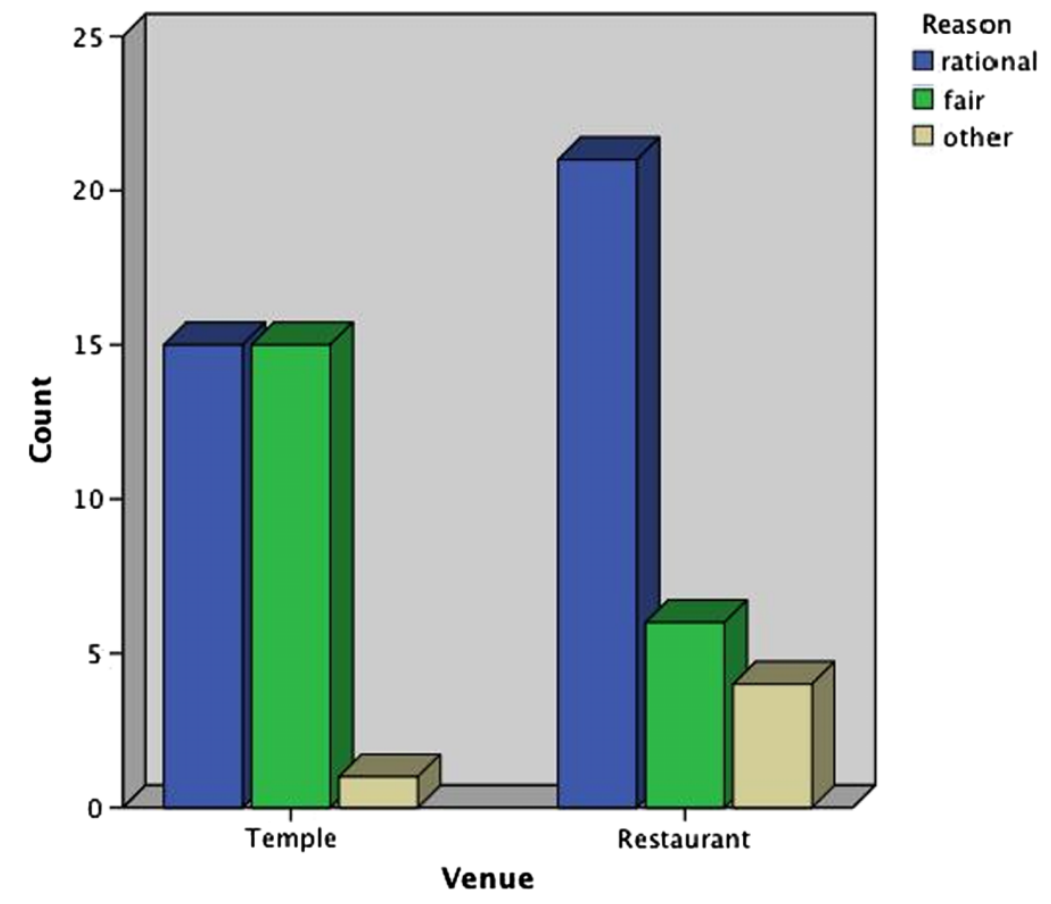

Figure 2. Players' stated reasons for their decisions. The Y axis describes the number of times each type of reason was provided by players in each venue. 
As predicted, participants playing in the temple setting were more cooperative than those playing in the restaurant setting. Furthermore, there were no effects of selfreported religiosity or ritual involvement on claims. This suggests that contextual cues typically associated with religion can motivate prosocial behavior independently of religious predisposition (Shariff \& Norenzayan, 2007). In other words, religion may in fact promote prosociality; however, this effect is not due to intrinsic religiosity but an artifact of contextual cues. It remains to be determined what mechanisms are driving this effect.

One possible mechanism might be related to social factors. The temple is a meeting place for the community, which might have an influence on prosociality simply by virtue of its association with sociality (Randolph-Seng \& Nielsen, 2008). Although this is generally a plausible explanation, this study attempted to control for such effects: the comparison group was not situated in a laboratory or any random venue but rather in a restaurant, a setting that was not only similar in arrangement but also an alternative locus for social interaction.

Given that prior practice did not predict cooperative behaviors, a more likely mechanism appears to be related to associative priming (Mckay, Efferson, Whitehouse, \& Fehr, 2011; Shariff \& Norenzayan, 2007). It has long been known that priming with subtle cues associated with normative themes may lead to an increase in prosocial behaviors (Bargh, Chen, \& Burrows, 1996). Since most religions involve doctrine pertaining to the moral domain of human behavior and provide ample mythological examples of generosity, religious primes may similarly trigger semantic associations with social norms related to fairness and cooperation.

Another plausible mechanism might be related to innate agency detection systems. Studies show that the mere depiction of a pair of eyes on a wall or screen can increase generosity and deter cheating (Bateson, Nettle, \& Roberts, 2006; Haley $\&$ Fessler, 2005). In this experiment, the temple contained visually prominent statues and icons of various Hindu gods, a prime which might trigger inborn sensitivities related to the detection of intentional agents in the environment (Barrett, 2004; Guthrie, 1993). Humans are innately attuned to detecting stimuli that indicate attention; these can signal risk of punishment or opportunities for reputation management (Haley \& Fessler, 2005). Similarly, religious images and symbols specifically trigger notions of supernatural agents, who are seen as powerful moral judges and arbiters of human behavior. Thus, it is argued that exposure to such cues may reinforce social norms and promote prosocial behavior by providing reminders of supernatural threats and rewards (Bulbulia, 2010; Johnson \& Bering, 2006; Norenzayan \& Shariff, 2008; Roes \& Raymond, 2003; Rossano, 2007).

It is important to emphasize that the mechanisms just described are not mutually exclusive. In fact, existing evidence suggests that they can all be expected to impact cooperative behavior (Ahmed \& Salas, 2008; Bateson et al., 2006; Bering et al., 2005; Haley \& Fessler, 2005; Malhotra, 2010; Randolph-Seng \& Nielsen, 2007; Shariff \& Norenzayan, 2007). Furthermore, such cues are often inherent components of religion. Whenever people enter the temple, they see statues and icons and make all sorts of automatic associations, and whatever cognitive baggage this carries, it is part and parcel of their religion and thus expected to have similar effects. Needless to say, we cannot rule out the possibility that religious belief may interact with other cognitive processes to enhance prosocial commitments (Bulbulia, 2012).

The evidence that participants who played in the temple invoked fairness more frequently than those in the restaurant in justifying their claims can also be seen as 
congruent with both of the above alternatives. Religious contexts can act as reminders of explicit prompts towards fairness (e.g., the Golden Rule) or mythological narratives about fairness. Furthermore, primes of agency and vigilance should presumably be expected to have similar effects whether they are of natural or supernatural origin, as humans and deities alike are associated with much the same interests (social and moral order), threats (punishment and retribution), and opportunities (reputation management and reciprocity).

Given the decision of participants in the religious venue to withdraw less money than those in the secular venue, it was interesting - and important for the overall interpretation of the results - to see what they expected the other party to withdraw. If their own claims had been based on an expectation of higher claims for the other party, then this choice might reflect risk aversion (withdrawing less out of fear that the other party might jeopardize their earnings). However, the analyses showed that this was not the case. This suggests that the decisions of those playing in the temple were not based merely on a rational, profit-maximizing calculation, but on motivations in some way separate from monetary considerations alone. Whether such concerns relate to the sense of fairness explicitly reported by those players or other motivations such as trust, altruism, fear of supernatural punishment (or any combination of these) remains unclear, and further research is needed to evaluate these possibilities.

Overall, this study investigated the effect of religious environments on cooperation by examining actual behavior in a real-world context. The design was built around the local ecology, using a natural instance of a religious context, while still maintaining a degree of control similar to a laboratory setting due to the bounded nature of the venues in which it was conducted. Building on previous methodologies, I aimed to combine the strengths while overcoming some of the shortcomings of previous field experiments that have (indirectly) addressed the link between religious priming and prosociality. For example, as opposed to previous correlational field studies (Ahmed, 2009; Sosis \& Ruffle, 2003), I was able to implement random assignment to avoid issues of self-selection; while in contract to Malhotra (2010), I addressed the possibility that a religious setting is effective simply because it is a locus of social interaction by using a control location with a comparable social function. My results offer experimental evidence for the effects of religious context on prosociality in an ecologically relevant setting, using natural contextual cues to supply the relevant religious information. Moreover, these findings reveal that in the specific Mauritian context, it is the ecological affordances of religious settings that evoke higher levels of prosocial response, irrespective of prior levels of religious belief or prior levels of religious practice. Future studies must investigate the generality of such effects, the proximate mechanisms by which religious ecologies evoke them, and the evolutionary dynamics that have lead to the remarkable impact of religious cues on cooperation.

\section{Acknowledgements}

Many thanks to the Maha Kali Mata Mandir and restaurant Le Brisant in Pointe aux Piments; Adriana Alcina Gomez, Prakash Bissessur, Vyash Bhaugeerutty, Neetoo Bhaugeerutty, and Panos Mitkidis for field assistance; Andreas Roepstorff for help and support at various stages of this research; Joseph Bulbulia and Ronald Fischer for reading and commenting on this paper; the two anonymous reviewers and editor Richard Sosis for their thorough and constructive feedback; and the people of Pointe aux Piments for their 
participation and hospitality. This project was supported by the MINDLab and the Religion, Cognition and Culture research unit (RCC) at Aarhus University; the Velux Foundation coregroup Technologies of the Mind; the LEVYNA Laboratory for the Experimental Research of Religion at Masaryk University (CZ.1.07/2.3.00/20.0048); and the Mauritian Laboratory for Experimental Anthropology (MALEXA).

\section{References}

Ahmed, A.M. (2009). Are religious people more prosocial? A quasi-experimental study with Madrasah pupils in a rural community in India. Journal for the Scientific Study of Religion, 48(2), 368-374.

Ahmed, A.M., \& Salas, O. (2008). In the back of your mind: Subliminal influences of religious concepts on prosocial behavior. Working Papers in Economics 331. Göteborg: Institutionen för natioanlekonomi med statiskik, Handelshögskolen vid Göteborgs universitat.

Allen, R.B. (1999). Slaves, freedmen, and indentured laborers in colonial Mauritius. African studies series. Cambridge: Cambridge University Press.

Anderson, L., Mellor, J., \& Milyo, J. (2010). Did the Devil make them do it? The effects of religion in public goods and trust games. Kyklos, 63(2), 163-175.

Ariely, D. (2008). Predictably irrational: The hidden forces that shape our decisions. New York: HarperCollins.

Ariely, D. (2012). The honest truth about dishonesty: How we lie to everyone - especially ourselves. New York: HarperCollins.

Bargh, J. A., Chen, M., \& Burrows, L. (1996). Automaticity of social behavior: Direct effects of trait construct and stereotype activation on action. Journal of Personality and Social Psychology, 71, $230-244$.

Barrett, J.L. (2004). Why would anyone believe in God?. Lanham, MD: AltaMira Press.

Bateson, M., Nettle, D., \& Roberts, G. (2006). Cues of being watched enhance cooperation in real-world setting. Biology Letters, 2, 412-414.

Batson, C.D., Floyd, R.B., Meyer, J.M., \& Winner, A.L. (1999). "And who is my neighbor?" Intrinsic religion as a source of universal compassion. Journal for the Scientific Study of Religion, $38,31-40$.

Batson, C., Oleson, K., \& Weeks, J. (1989). Religious prosocial motivation: Is it altruistic or egoistic? Journal of Personality, 57(5), 873-884.

Batson, C., Schoenrade, P., \& Ventis, W.L. (1993). Religion and the individual: A social-psychological perspective. New York: Oxford University Press.

Bering, J., McLeod, K., \& Shackelford, T.K. (2005). Reasoning about dead agents reveals possible adaptive trends. Human Nature, 16(4), 360-381.

Budescu, D.V., Rapoport, A., \& Suleiman, R. (1992). Simultaneous vs. sequential requests in resource dilemmas with incomplete information. Acta Psychologica, 80, 297-310.

Bulbulia, J. (2010). Charismatic signaling. Journal for the Study of Religion, Nature and Culture, 3(4), $518-551$.

Bulbulia, J. (2012). Spreading order: Religion, cooperative niche construction, and risky coordination problems. Biology and Philosophy, 27(1), 1-27.

Bulbulia, J., \& Mahoney, A. (2008). Religious solidarity: The hand grenade experiment. Journal of Cognition and Culture, 8, 295-320.

Central Statistical Office of Mauritius (2002). 2000 housing and population census, Republic of Mauritius, analysis report. Port Louis: Central Statistical Office.

Christopher, A. (1992). Ethnicity, community and the census in Mauritius, 1830-1990. Geographical Journal, 158(1), 57-64.

Darley, J.M., \& Batson, C.D. (1973). From Jerusalem to Jericho: A study of situational and dispositional variables in helping behavior. Journal of Personality and Social Psychology, 27, 100-108.

de Dreu, C.K.W., Yzerbyt, V., \& Leyens, J.-P. (1995). Dilution of stereotype-based cooperation in mixedmotive interdependence. Journal of Experimental Social Psychology, 31, 575-593.

Durkheim, E. (1912/1995). The elementary forms of religious life. (Karen E. Fields, Trans.). New York: Free Press.

Eckel, C.C., \& Grossman, P.J. (2004). Giving to secular causes by the religious and nonreligious: An experimental test of the responsiveness of giving to subsidies. Ethnography, 33(2), 271-289.

Eriksen, T.H. (1994). Nationalism, Mauritian style: Cultural unity and ethnic diversity. Comparative Studies in Society and History, 36(3), 549-574.

Eriksen, T.H. (1998). Common denominators: Ethnicity, nation building and compromise in Mauritius. Oxford: Berg.

Freud, S. (1927/1961). The future of an illusion. (J. Strachey, Trans.). New York: Norton.

Friedrichs, R.W. (1960). Alter versus ego: An exploratory assessment of altruism. American Sociological Review, 25(4), 496-508. 
Furrow, J.L., King, P.E., \& White, K. (2004). Religion and positive youth development: Identity, meaning, and prosocial concerns. Applied Developmental Science, 8, 17-26.

Ginges, J., Hansen, I., \& Norenzayan, A. (2009). Religion and support for suicide attacks. Psychological Science, 20(2), 224-230.

Goldfried, J., \& Miner, M. (2002). Quest religion and the problem of limited compassion. Journal for the Scientific Study of Religion, 41, 685-695.

Gronbjerg, K. A., \& Never, B. (2004). The role of religious networks and other factors in types of volunteer work. Nonprofit Management and Leadership, 14, 263-289.

Grossman, P.J., \& Parrett, M.B. (2011). Religion and prosocial behaviour: A field test. Applied Economics Letters, 18(6), 523-526.

Guiso, L., Sapienza, P., \& Zingales, Z. (2003). People's opium? Religion and economic attitudes. Journal of Monetary Economics, 50, 225-282.

Gurven, M., \& Winking, J. (2008). Collective action in action: Prosocial behavior in and out of the laboratory. American Anthropologist, 110, 179-190.

Guthrie, S.E. (1993). Faces in the clouds: A new theory of religion. New York: Oxford. University Press.

Haley, K.J., \& Fessler, D.M.T. (2005). Nobody's watching? Subtle cues affect generosity in an anonymous economic game. Evolution and Human Behavior, 26, 245-256.

Henrich, J., Boyd, R., Bowles, S., Camerer, C., Fehr, E., \& Gintis, H. (Eds.) (2004). Foundations of human sociality: Economic experiments and ethnographic evidence from fifteen small-scale societies. Oxford: Oxford University Press.

Jackson, L.M., \& Esses, V.M. (1997). Of scripture and ascription: The relation between religious fundamentalism and intergroup helping. Personality and Social Psychology Bulletin, 23, 893-906.

James, W. (1902/1985). The varieties of religious experience: A study in human nature. Cambridge, MA: Harvard University Press.

Johansson-Stenman, O., Mahmud, M, \& Martinsson, P. (2009). Trust and religion: Experimental evidence from Bangladesh. Economica, 76(303), 462-485.

Johnson, D.D.P., \& Bering, J.M. (2006). Hand of God, mind of man: punishment and cognition in the evolution of cooperation. Evolutionary Psychology, 4, 219-233.

Koenig, L.B., McGue, M., Krueger, R.F., \& Bouchard, T.J. (2007). Religiousness, antisocial behavior, and altruism: Genetic and environmental mediation. Journal of Personality, 75(2), 265-290.

Lam, P.Y. (2002). As the flocks gather: How religion affects voluntary association participation. Journal for the Scientific Study of Religion, 41(3), 405-422.

Malhotra, D. (2010). (When) are religious people nicer? Religious salience and the "Sunday effect" on prosocial behavior. Judgment and Decision Making, 5(2), 138-143.

Mazar, N., Amir, O., \& Ariely, D. (2008). The dishonesty of honest people: A theory of self-concept maintenance. Journal of Marketing Research, 45, 633-644.

McCullough, M.E., \& Worthington, E.L. (1999). Religion and the forgiving personality. Journal of Personality, 67, 1141-1164.

Mckay, R., Efferson, C., Whitehouse, H., \& Fehr, E. (2011). Wrath of God: Religious primes and punishment. Proceedings of the Royal Society B. doi: 10.1098/rspb.2010.2125.

Messick, D.M., Allison, S.T., \& Samuelson, C.D. (1988). Framing and communication effects on group members' responses to environmental \& social uncertainty. In S. Maital (Ed.), Applied behavioural economics (Vol. 2, pp. 677-700). New York: New York University Press.

Monsma, S.V. (2007). Religion and philanthropic giving and volunteering: Building blocks for civic responsibility. Interdisciplinary Journal of Research on Religion, 3, 2-28.

Morgan, S.P. (1983). A research note on religion and morality: Are religious people nice people? Social Forces, 61, 683-692.

Norenzayan, A., \& Shariff, A.F. (2008). The origin and evolution of religious prosociality. Science, 322, $58-62$.

Okediji, T.O. (2005). The dynamics of ethnic fragmentation. American Journal of Economics and Sociology, 64(2), 637-662. Wiley Online Library.

Orbell, J., Goldman, M., Mulford, M., \& Dawes, R. (1992). Religion, context, and constraint toward strangers. Rationality and Society, 4(3), 291-307.

Ostrom, E., Gardner, R., \& Walker, J. (1994). Rules, games, and common-pool resources. Ann Arbor: University of Michigan Press.

Pichon, I., Boccato, G., \& Saroglou, V. (2007). Nonconscious influences of religion on prosociality: A priming study. European Journal of Social Psychology, 37, 1032-1045.

Randolph-Seng, B., \& Nielsen, M.E. (2007). Honesty: One effect of primed religious representations. International Journal for the Psychology of Religion, 17(4), 303-315.

Randolph-Seng, B., \& Nielsen, M.E. (2008). Is God really watching you? A response to Shariff and Norenzayan (2007). International Journal for the Psychology of Religion, 18(2), 119-122.

Robertson Smith, W. (1889). Lectures on the religion of the Semites: First Series. Fundamental Institutions. London: Adam \& Charles Black.

Roes, F.L., \& Raymond, M. (2003). Belief in moralizing gods. Evolution and Human Behavior, 24, $126-135$. 
Rossano, M. (2007). Supernaturalizing social life: religion and the evolution of human cooperation. Human Nature, 18, 272-294.

Ruffle, B. \& Sosis, R. (2010). "Do religious contexts elicit more trust and altruism? An experiment on Facebook." Discussion Paper No. 10-02, Department of Economics: Ben-Gurion University.

Saroglou, V., Delpierre, V., \& Demelle, R. (2004). Values and religiosity: A meta-analysis of studies using Schwartz's model. Personality and Individual Differences, 37, 721-734.

Saroglou, V., Pichon, I., \& Trompette, L. (2005). Prosocial behavior and religion: New evidence based on projective measures and peer ratings. Journal for the Scientific Study of Religion, 44(3), 323-348.

Skinner, B.F. (1969). Contingencies of reinforcement: A theoretical analysis. New York: Appleton-CenturyCroft.

Shariff, A., \& Norenzayan, A. (2007). God is watching you. Psychological Science, 18(9), 803-809.

Soler, M. (2012). Costly signaling, ritual and cooperation: Evidence from Candomblé, an Afro-Brazilian religion. Evolution and Human Behavior, 33(4), 346-356.

Sosis, R., \& Ruffle, B. (2003). Religious ritual and cooperation: Testing for a relationship on Israeli religious and secular kibbutzim. Current Anthropology, 44(5), 713-722.

Spilka, B., Hood, R.W., Hunsberger, B., \& Gorsuch, R. (2003). The psychology of religion: An empirical approach. New York: Guilford Press.

Tan, J.H. (2006). Religion and social preferences: An experimental study. Economics Letters, 90, 60-67.

Tan, J., \& Vogel, C. (2008). Religion and trust: An experimental study. Journal of Economic Psychology, 29, $832-848$.

Turner, V. (1969). The ritual process. Chicago: Aldine.

Ware, J., \& Dethmer, J. (2009). The Trust Project: Rebuilding trust one financial professional at a time [White paper]. Retrieved from www.abfgla.com/uploads/20090618_TrustProject.pdf

Xygalatas, D., Mitkidis, P., Fischer, R., Bulbulia, J., Reddish, P., Skewes, J., \& Roepstorff, A. (in press). Extreme rituals promote prosociality. 